\title{
A Comparative Study of Auramine Staining Using Light Emitting Diode (LED) Fluorescent Microscopy with Ziehl-Neelsen Staining for Detection of Acid Fast Bacilli in Sputum in a Tertiary Care Hospital, Karimnagar
}

\author{
A.R.K. Archana, Amar C. Sajjan", R. Kondal Rao, B. Archana and G. Swetha \\ Department of Microbiology, Chalmeda Anand Rao Institute of Medical Sciences, \\ Karimnagar, Telangana, India \\ *Corresponding author
}

\section{A B S T R A C T}

Keywords

ZN staining,

Fluorescent AO,

LED fluorescent microscopy

Article Info

Accepted:

04 August 2018

Available Online:

10 September 2018
Tuberculosis (TB) still remains a global health problem affecting one third of world population. Early diagnosis of TB is very important for therapeutic reasons and to control the spread of infection. For developing countries with a large number of cases and financial constraints, evaluation of rapid and inexpensive diagnostic methods has a great importance. Aim of this research is to study the efficacy of Ziehl Neelsen (ZN) method versus fluorescent staining in the detection of acid fast bacilli (AFB) in sputum samples. A total of 675 sputum samples collected from suspected cases of pulmonary tuberculosis which were subjected to Ziehl Neelsen and fluorescent auramine $\mathrm{O}(\mathrm{AO})$ staining for the detection of acid fast bacilli. Out of 675 samples, 58 (8.59\%) were positive for AFB on the Ziehl Neelsen method, while the positivity increased to $93(13.77 \%)$ on the fluorescent AO method. AO was found to be superior to Ziehl Neelsen on several aspects. AO staining was able to detect more paucibacillary than Ziehl Neelsen staining. Since screening was done under lower power of magnification (400x), fluorescent $\mathrm{AO}$ technique has a better diagnostic value and is less time consuming compared to Ziehl Neelsen in diagnosing pulmonary tuberculosis patients. Hence, the efficacy of AO staining under fluorescence microscopy proved to be much higher than Ziehl Neelsen staining under conventional light microscopy.

\section{Introduction}

Tuberculosis is a disease of the respiratory system, caused by Mycobacterium tuberculosis. It has a great impact on morbidity and mortality in the developing world (Roma Goyal, 2013). It is estimated that nearly one billion people will be infected with tuberculosis (TB), and 200 million develop the disease and 35 million will die from $\mathrm{TB}$ during 2000-2020.

Our country has a high burden of TB with a prevalence of 211 cases per 100,000 population and 171 incident cases during 2013 (Jagdeesha, 2015). 
The situation is further worsening due to increase of drug resistant variants (MDR) of Mycobacterium tuberculosis. This year, 2018 CDC selected the theme "Wanted: Leaders for a TB free world". The need of the hour is a good efficient affordable test which could diagnose the disease early so that effective treatment could be started immediately. With the advancement in technology a large number of tests have been developed for the diagnosis of tuberculosis. (Ashish Khanna, 2016).

Thus sputum microscopy is the main case finding tool in tuberculosis control programmes. In India under Revised National Tuberculosis Control programme (RNTCP), Ziehl Neelsen method is the recommended procedure for staining tubercle bacilli. However, for a better implementation of control programme, there is a need for a better case finding tool. Therefore fluorescence microscopy is a rapid, useful and reliable tool for the detection of acid fast bacilli (AFB) (Soham Gupta, 2010; Saroj Golia, 2013).

Auramine O stain is advantageous over Ziehl Neelsen (ZN) stain as it is simpler, cost effective and can be visualised even at low magnifications than $\mathrm{ZN}(40 \mathrm{x} / 100 \mathrm{x})$. Auramine $\mathrm{O}$ stain enters the bacterial cell wall and the bacilli appears bright, glowing yellow against dark background under UV light, whereas on $\mathrm{ZN}$ stain bacilli appear as pink coloured rods. Thus, fluorescent microscopy is more sensitive and takes $75 \%$ lesser time and also enhances the improvement of diagnosis in samples over ZN staining (Upasana Bhumbla, 2014). Replacement of mercury vapor lamp with a LED illumination system decreases the cost and increases the life span (WHO policy statement, 2011). The LED fluorescent microscopy is known to increase the positivity rate up to $10 \%$. WHO endorsed the LED fluorescent microscopy over conventional light microscopy for detection of acid fast bacilli on clinical specimens. Fluorescent microscopes are provided by the government to the state reference laboratories under Revised National Tuberculosis Control programme (RNTCP) (Alvarez Gerardo, 2012) (Pratik Kumar, 2017).

Therefore the present study was undertaken to see the efficacy of Ziehl Neelsen method verses fluorescent staining in the detection of acid fast bacilli in sputum sample (Table 1 and 2).

\section{Materials and Methods}

A comparative study done during the period from March 2017 to February 2018 conducted in a tertiary care hospital. A total of 675 sputum samples irrespective of all age groups were collected.

\section{Inclusion criteria}

Only sputum samples,

Clinically suspected and or radiological evidence of pulmonary tuberculosis cases were included.

\section{Exclusion criteria}

Other than sputum samples.

HIV TB co-infected patient.

Two samples were collected; One spot and the second one early morning, fasting sample in a clean, sterile, heat proof and wide mouth containers. The processing of samples is carried out in a Biosafety cabinet - II taking all necessary precautions. Each sample is then subjected to $\mathrm{ZN}$ staining and fluorescent Auramine- $\mathrm{O}(\mathrm{AO})$ staining.

\section{Preparation of fluorescent smear}

The heat fixed smear was flooded with Auramine - $\mathrm{O}$ for twenty minutes. Then rinsed 
well with running tap water care was taken so as not to wash away smear. Decolourise with acid alcohol for three minutes and rinse in running tap water. Quench with $0.5 \%$ potassium permanganate, air dried and examined under high power. Acid fast bacilli (AFB) typically fluoresce as golden, slender rod shaped structure. Smear is graded as per Revised National Tuberculosis Control Program (RNTCP) criteria.

\section{Results and Discussion}

Results were graded according to Revised National Tuberculosis Control Program (RNTCP) guidelines for ZN staining. A total of 675 sputum samples obtained from patients were processed by both fluorescent and $\mathrm{ZN}$ staining.

Table 3 shows out of 675 samples, the smear positivity for acid fast bacilli on the conventional Ziehl Neelsen (ZN) method is $8.59 \%(58 / 675)$ while the positivity increased to $13.77 \%(93 / 675)$ on the fluorescent method. Table 5 shows out of 49 paucibacillary cases, $37(39.78 \%)$ were positive by fluorescent method.

Therefore fluorescent microscopy is superior to Ziehl Neelsen method (Fig. 1 and 2; Table 4).

Table.1 Grading chart, Revised National Tuberculosis Control Program (RNTCP) for $\mathrm{ZN}$ staining

\begin{tabular}{|l|l|l|l|}
\hline EXAMINATION & RESULT & GRADING & $\begin{array}{l}\text { NO.OF FIELDS TO } \\
\text { BE OBSER VED }\end{array}$ \\
\hline Zero AFB / 100 HPF & NEGATIVE & 0 & 100 \\
\hline 1-9 AFB / 100 HPF & SCANTY & $\begin{array}{l}\text { RECORD EXACT } \\
\text { NUMBER SEEN }\end{array}$ & 200 \\
\hline 10-99 AFB / 100HPF & POSITIVE & $1+$ & 100 \\
\hline 1-10 AFB /1HPF & POSITIVE & $2+$ & 50 \\
\hline >10AFB /1 HPF & POSITIVE & $3+$ & 20 \\
\hline
\end{tabular}

$\mathrm{HPF}=$ high power field, $\mathrm{AFB}=\mathrm{Acid}$ fast bacilli.

Table.2 Grading chart (WHO, IUATLD, 2007) for led fluorescent microscopy

\begin{tabular}{|c|c|c|}
\hline $\begin{array}{l}\text { Result (WHO } \\
\text { scale) } \\
1000 \times \text { field = } \\
\text { HPF }\end{array}$ & $\begin{array}{l}\text { LED fluorscent microscopy } \\
\begin{aligned}(400 \mathrm{x}: & 1 \text { length }=40 \text { Fields } \\
& =200 \mathrm{HPF})\end{aligned}\end{array}$ & $\begin{array}{l}\text { Minimum number } \\
\text { of fields to be } \\
\text { examined }\end{array}$ \\
\hline Negative & Zero AFB / 1 length & 40 \\
\hline Scanty & 1-19 AFB/1 length & 40 \\
\hline $1+$ & 20-199 AFB/1 length & 40 \\
\hline $2+$ & 5-50 $\mathrm{AFB} / 1$ field on average & 20 \\
\hline $3+$ & $>50 \mathrm{AFB} / 1$ field on average & 8 \\
\hline
\end{tabular}

For the present study $2+$ and $3+$ were classified as multibacillary and $1+$ and scanty as paucibacillary. (Prasanthi, 2005). 
Table.3 Comparison of Ziehl Neelsen (ZN) and Auramine staining reports

\begin{tabular}{|l|l|l|}
\hline Staining method used & No. of Positive smears (\%) & No. of Negative smears (\%) \\
\hline Ziehl Neelsen stain & $58(8.59 \%)$ & $617(91.40 \%)$ \\
\hline A uramine stain & $93(13.77 \%)$ & $589(86.22 \%)$ \\
\hline
\end{tabular}

Table.4 Distribution of positive slides by grading and technique used

\begin{tabular}{|l|l|l|}
\hline Grading & ZN staining & Auramine staining \\
\hline Scanty & $2(3.44 \%)$ & $13(13.97 \%)$ \\
\hline $1+$ & $10(17.24 \%)$ & $24(25.80 \%)$ \\
\hline $2+$ & $18(31.03 \%)$ & $22(23.65 \%)$ \\
\hline $3+$ & $28(48.27 \%)$ & $34(36.55 \%)$ \\
\hline Total & 58 & 93 \\
\hline
\end{tabular}

Table.5 Distribution of paucibacillary and multibacillary cases detected by ZN Staining and LED fluorescent microscopy.

\begin{tabular}{|l|c|c|c|}
\hline Staining method & $\begin{array}{c}\text { No. of } \\
\text { paucibacillary } \\
\text { Cases }\end{array}$ & $\begin{array}{c}\text { No. of } \\
\text { multibacillary } \\
\text { Cases }\end{array}$ & $\begin{array}{c}\text { Total no. of } \\
\text { positive cases } \\
\text { detected }\end{array}$ \\
\hline ZN staining & $12(20.68 \%)$ & $46(79.31 \%)$ & 58 \\
\hline Auramine staining & $37(39.78 \%)$ & $56(65.11 \%)$ & 93 \\
\hline
\end{tabular}

Table.6 Showing comparative results with Ziehl Neelsen staining and fluorescent staining in different studies

\begin{tabular}{|l|c|c|c|c|}
\hline \multicolumn{1}{|c|}{ Author } & Year & $\begin{array}{c}\text { Z-N } \\
\text { Staining } \\
\text { Positive (\%) }\end{array}$ & $\begin{array}{c}\text { Fluorescent } \\
\text { staining } \\
\text { positive (\%) }\end{array}$ & $\begin{array}{c}\text { Increase in } \\
\text { positivity by } \\
\text { fluorescent } \\
\text { microscopy (\%) }\end{array}$ \\
\hline Soham Gupta et al., & 2010 & 5.7 & 6.1 & 0.4 \\
\hline Surya kumar et al., & 2012 & 11 & 17 & 6 \\
\hline Saroj Goyal et al., & 2013 & 10.57 & 16.56 & 6 \\
\hline Ashish Khanna et al., & 2016 & 26.5 & 35.9 & 10 \\
\hline Present study & 2016 & 8.59 & 13.77 & 5.18 \\
\hline
\end{tabular}


Fig.1 Fluorescent microscopy- Paucibacillary

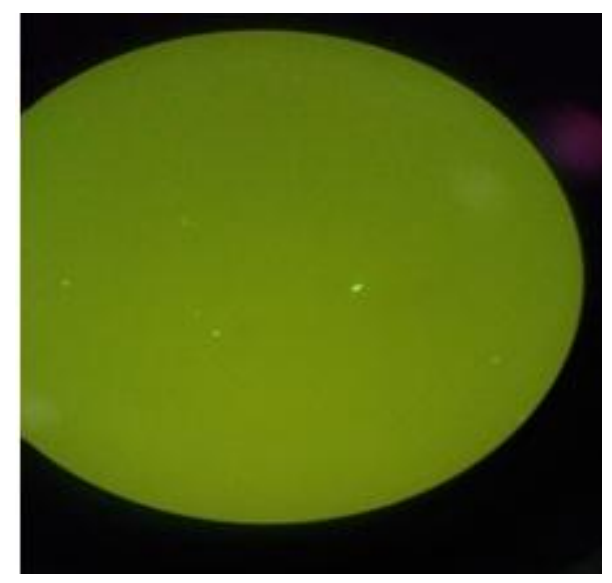

Fig.2 Fluorescent microscopy- Multibacillary

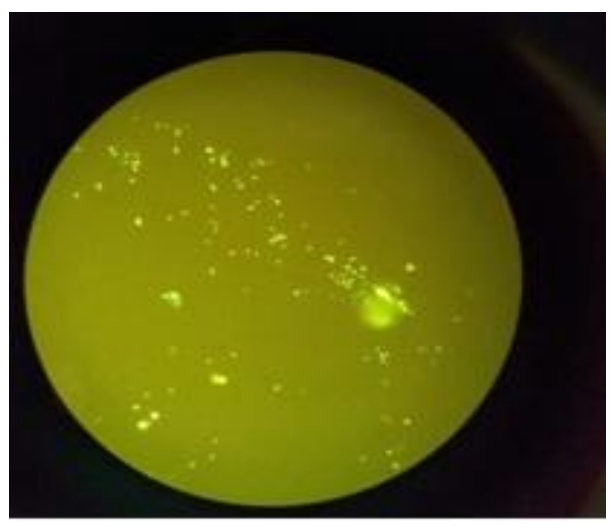

India continues to have the highest number of tuberculosis cases in the world according to Global tuberculosis report 2017. Screening of sputum by radiometric and molecular methods on regular basis is not possible in developing countries like India because of its high cost.

So Ziehl Neelsen staining is done as it is most rapid, economic and reliable method in designated microscopy centres (DMC) and Government based health care provides coming under Revised National Tuberculosis Control Program (RNTCP). Now fluorescent methods have adopted by many DMC's. Hence comparative study between Ziehl Neelsen and fluorescent methods are undertaken to know the efficacy of fluorescent microscopy in early detection of tuberculosis cases. Present study showed, AO staining with LED microscopy(39.78\%) was more efficient over $\mathrm{ZN}$ stain $(20.68 \%)$ in determining paucibacillary cases which is accordance with previously conducted studies (Saroj Golia, 2013; Roma goyal, 2013).

While Table 6 shows a study conducted by Ashish khanna et al., in 2016, in Punjab showed more $(10 \%)$ fluorescent positivity compared to Ziehl Neelsen positivity as the study was done on less number of specimens and also a study conducted by Soham Gupta et al., in 2010 in Karnataka showed least $(0.4 \%)$ fluorescent positivity compared to Ziehl Neelsen positivity. But both the above findings still support with the previous studies 
that demonstrated the superior diagnostic performance of fluorescent microscopy compared to conventional light microscopy.

\section{Acknowledgment}

We would like to thank Mr Sandeep Pulluri, DMC for the support during the study.

There is an urgent need for control of tuberculosis by early detection and prompt treatment. However, the routine method of Ziehl Neelsen examination i.e., Ziehl Neelsen staining is not sensitive enough and moreover they remain undiagnosed and fail to treatment. Therefore switch to LED fluorescent microscopy be made according to a carefully phased implementation plan.

\section{References}

Ashish Khanna, Poonam Sharma, Sarabjit Sharma, Menka Khanna, 2016. Comparison of conventional Ziehl Neelsen staining with LED Fluorescent staining for pulmonary tuberculosis cases. Indian J Microbiol Res. 3(4): 363-367, DOI: 10.18231/2394-5478.

Gerardo Alvarez-Uria,Jose, M.Azcona Manoranjan Midde, Praveen K. Naik, Srinivasulu Reddy, Raghuprakash Reddy 2012; Rapid Diagnosis Pulmonary and Extrapulmonary Tuberculosis in HIV-Infected Patients: Comparison fluorescent microscopy and the GeneXpert MTB/RIF Assay in a District Hospital in India, Tuberculosis Research and Treatment Volume 2012.

Jagdeesha K, Vidya Pai, 2015; A comparative study of fluorescent staining and Ziehl Neelsen's staining for detection of acid fast bacilli in sputum in a tertiary care hospital in Mangalore ; International Journal of Microbiology \& Parasitology; 1(1)1-3.
Prasanthi K, Kumari AR, 2005. Efficacy of fluorochrome stain in the diagnosis of pulmonary tuberculosis coinfected with HIV: Indian Journal of Medical Microbiology, 23 (3):179-185.

Pratik Kumar, Prashant Goswami, Mukesh Kumar, Rashmi Kumari, Syed K Ali, 2017. Effectiveness of Xpert MTB/Rif on smear negative samples tested by LED fluorescence microscopy for rapid diagnostics of TB cases in Bihar: Journal of Scientific and Engineering Research, 4(1): 78-80 DOI: 10.21474/IJAROI/4511

Pratik Kumar, Prashant Goswami, Rashmi Kumari, Maneesh Kumar and Subham Kumar, 2017. Comparative study of LED fluorescent microscopy with the conventional $\mathrm{ZN}$ based microscopy for diagnosing microbiologically confirmed tb case; International Journal of Advanced Research. 5(6), 1083-1086.

Roma Goyal, Anil Kumar, 2013. A Comparison of Ziehl-Neelsen Staining and Fluorescent Microscopy for Diagnosis of Pulmonary Tuberculosis; IOSR Journal of Dental and Medical Sciences (IOSR-JDMS) 8(5), 05-08

Saroj Golia, Vivek Hittinahalli, Nirmala A.R, Sangeetha K.T, Asha S Kamath B, 2013. Comparative study of auramine staining using led fluorescent microscopy with Ziehl- Neelsen staining in the diagnosis of pulmonary tuberculosis; Journal of Evolution of Medical and Dental Sciences. 2 (20): 3450-3456/

Soham Gupta, Vishnu Prasad Shenoy, Indira Bairy, Muralidharan S, 2010. Diagnostic efficacy of Ziehl-Neelsen method against fluorescent microscopy in detection of acid fast bacilli; Asian Pacific Journal of Tropical Medicine, 328-329.

Suria K, Chandrasekar C, Rajasekaran S, 2012. Comparison of conventional and 
fluorescent staining methods in diagnosis of pulmonary tuberculosis among HIV seropositive individuals. Journal of evolution of medical and dental sciences. 1(4):463-66.

Upasana Bhumbla and Gyaneshwari, 2014; A comparative study of Ziehl-Neelson staining and auramine staining in sputum sample for the diagnosis of pulmonary tuberculosis; International Journal of Biomedical Research. 5(6) (DOI: 10.7439/ijbr).

World Health Organization 2011. Fluorescent light-emitting diode (LED) microscopy for diagnosis of tuberculosis: policy statement. WHO/HTM/TB/2011.8

\section{How to cite this article:}

Archana, A.R.K., Amar C. Sajjan, R. Kondal Rao, B. Archana and Swetha, G. 2018. A Comparative Study of Auramine Staining Using Light Emitting Diode (LED) Fluorescent Microscopy with Ziehl-Neelsen Staining for Detection of Acid Fast Bacilli in Sputum in a Tertiary Care Hospital, Karimnagar. Int.J.Curr.Microbiol.App.Sci. 7(09): 117-123. doi: https://doi.org/10.20546/ijcmas.2018.709.015 